\title{
THE CORRELATION OF VLF PROPAGATION VARIATIONS WITH ATMOSPHERIC PLANETARY-SCALE WAVES
}

\author{
D. J. Cavalieri \\ R. J. Deland \\ Polytechnic Institute of New York \\ T. A. Potemra \\ R. F. Gavin \\ Johns Hopkins University, Applied Physics Laboratory
}

\begin{abstract}
Variations in the received daytime phase of long distance, cesium-controlled, VLF transmissions are compared to the height variations of the $10-\mathrm{mb}$ isobaric surface during the first three months of 1965 and 1969. The VLF phase values are also compared to height variations of constant electron densities in the Eregion from Brown and Williams (1971) and to variations of $f-m i n$ from Deland and Friedman (1972) which have been shown to be well correlated with planetary-scale variations in the stratosphere by Deland and Cavalieri (1973). The VLF phase variations show good correlation with these previous ionospheric measurements and with the $10-\mathrm{mb}$ surfaces. The VLF variations appear to lag the stratospheric variations by about 4 days during the 1965 period, but lead the latter by about 4 days during the 1969 period.
\end{abstract}

The planetary scale waves in the stratosphere are shown to be travelling on the average eastward in 1965 and westward in 1969. The above correlations are interpreted as due to the propagation of travelling planetary scale waves with westward tilted wave fronts. Upward energy transport due to the vertical structure of those waves is also discussed.

These correlations provide further evidence for the coupling between the lower ionosphere at about $70 \mathrm{~km}$ altitude (the daytime VLF reflection height) and the stratosphere, and they demonstrate the importance of planetary wave phenomena to VLF propagation.

\section{INTRODUCTION}

Numerous observations support the view that ionization variations in the $D$ and E-regions are coupled to metoerological variations in the stratosphere. Evidence for this coupling is the connection of ionospheric variations, which have been determined almost exclusively from ground-based $\mathrm{MF}$ or $\mathrm{HF}\left(>_{1 \mathrm{MHz}}\right.$ ) radio 
transmissions, to pressure or temperature variations in the stratosphere (Bowtilil, 1969; Gregory and Manson, 1969; Schwentek, 1969; Thomas, 1971; Lauter and Taubenhiem, 1971). Brown and Williams (1971) have correlated variations in the height of a constant electron density surface in the E-region, estimated from ionosonde observations, with height variations of the 10-mb isobaric surface in the stratosphere. Deland and Cavalier1 (1973) have further shown the electron density heights determined by Brown and Williams to be well correlated with planetary-scale fluctuations of $\mathrm{f}-\mathrm{min}$ (the minimum frequency at which reflection from the ionosphere is recorded by an ionosonde). Deland and Friedman (1972) have shown these same f-min variations to be correlated directly with atmospheric pressure fields for the stratosphere.

Long distance VLF (3-30 kHz) tranemissions have been used for many years to study a variety of ionospheric disturbances related to solar $x$-rays, solar energetic particles, trapped energetic particles, aurora, and magnetic storms (e.g. Bracewell et al., 1951; Crombie, 1965; Belrose and Thomas, 1968; Westerlund et al., 1969; Zmuda and Potemra, 1972; Potemra and Rosenberg, 1973). The longest time scale of these disturbances is about 10 days and is only observed during severe polar cap absorption events with trans-polar VLF transmissions or following large geomagnetic storms with midlatitude transmissions. Analysis of longer-period (>10 days) or seasonal ionospheric variations observed with VLF signals has been limited by the long-term stability of transmitter and receiver reference oscillators and are rare (e.g., Reder and Westerlund, 1970). Brady and Crombie (1963) corrected transmitter and receiver oscillator drifts by subtracting a parabolic variation of phase drift in order to study the effects of lunar tidal variations on the phase of VLF transmissions. The more recent use of cesium atomic standards for frequency reference at transmitters and receivers has enabled seasonal variations to be analyzed using VLF data with greater confidence (e. g. , Noonkester, 1972). However, no connections have yet been made between disturbances observed with VLF transmissions and planetary scale fluctuations in the stratospherc. Since correlations have already been established between stratospheric phenomena and ionospheric variations determined from MF and HF transmissions, it seems reasonable that variations in VLF transmissions can be related to and be used to study the coupling between ionosphere and atmosphere.

Theoretical work by Charney and Drazin (1961) indicates that strong zonal winds in the winter months tend to inhibit the upward propagation of quasi-stationary planetary scale waves, however, more recently Dickinson (1968a, 1968b), Matsuno (1970) and Hirota (1971) with improved models have shown that the stratosphere and mesophere are likely to be permeable to these planetary scale fluctuations. Other studies by Boville (1966) and Deland and Johnson (1968) have shown that transient planetary scale waves moving westward on the average exist in the lower stratosphere and are likely to extend into the upper atmosphere with large amplitudes in winter (e.g., Deland, (1970)). 
Eliassen and Palm (1960) have related the upward propagation of energy to the vertical structure of quasi-stationary planetary scale waves. Deland (1973) has shown that the theoretical results of Eliassen and Palm (1960) are also applicable to transient planetary scale waves. The results presented below are consistent with upward propagation of energy into the lower ionosphere.

In this paper, variations in the received daytime phase of a long-distance VLF transmission are compared with the height variations of constant densities from Brown and Williams (1971), the variations of $\mathrm{f}-\mathrm{min}$ from Deland and Friedman (1972), and the height variations of the $10-\mathrm{mb}$ isobaric surface from Deland and Cavalieri (1973), which were all observed during the first three months of 1965. Daytime VLF phase values are also compared to variations in the $10-\mathrm{mb}$ iosbaric surface for the first three months of 1969 .

\section{VLF PHASE DATA}

The paths of VLF transmissions monitored at the Applied Physics Laboratory (APL) and nearby at the U.S. Naval Observatory (USNO) in Washington, D.C. are illustrated in Figure 1 with projections of magnetic $L$ shells on the ionosphere at $100 \mathrm{~km}$ altitude. The frequency, path length, highest geographic latitude, highest $L$ shell (and corresponding invariant latitude) for each VLF path are listed in Table 1. The phase advance produced by a uniform $1 \mathrm{~km}$ lowering of the daytime VLF reference height is also listed in this table and was computed in the following manner.

VLF transmissions are often analyzed as waves propagating in the waveguide formed by the earth's surface and the lower ionosphere. The total phase delay $\tau$ between transmitter and receiver separated by a distance $d_{0}$ is $\tau=d_{0} / v_{0}$ secs., where $v_{0}$ is the VLF phase velocity for undisturbed conditions. Variations in the ionosphere over this path which result in a different VLF phase velocity $v$ will be observed as a change in the phase delay at the receiver, $\Delta \tau$, and is expressed by the formula, $\Delta \tau=d_{0}\left(1 / v-1 / v_{0}\right)$ secs. A uniform lowering of the effective VLF waveguide height, due for example to ionization enhancements, will increase the VLF phase velocity and cause the phase to advance (1.e. a negative phase delay) at the receiver measured with respect to the undisturbed value. The time scale of these disturbances is less than a few hours, so that their effects are not important to the present analysis of variations of a few days.

The VLF reflection height for undisturbed daytime conditions is usually taken as about $70 \mathrm{~km}$ (Potemra et al., 1970; Johler, 1970, Westerlund and Reder, 1973). Using phase velocity values for the lowest order VLF modes from Wait and Spies (1964) and Spies (private communication, 1964) which 


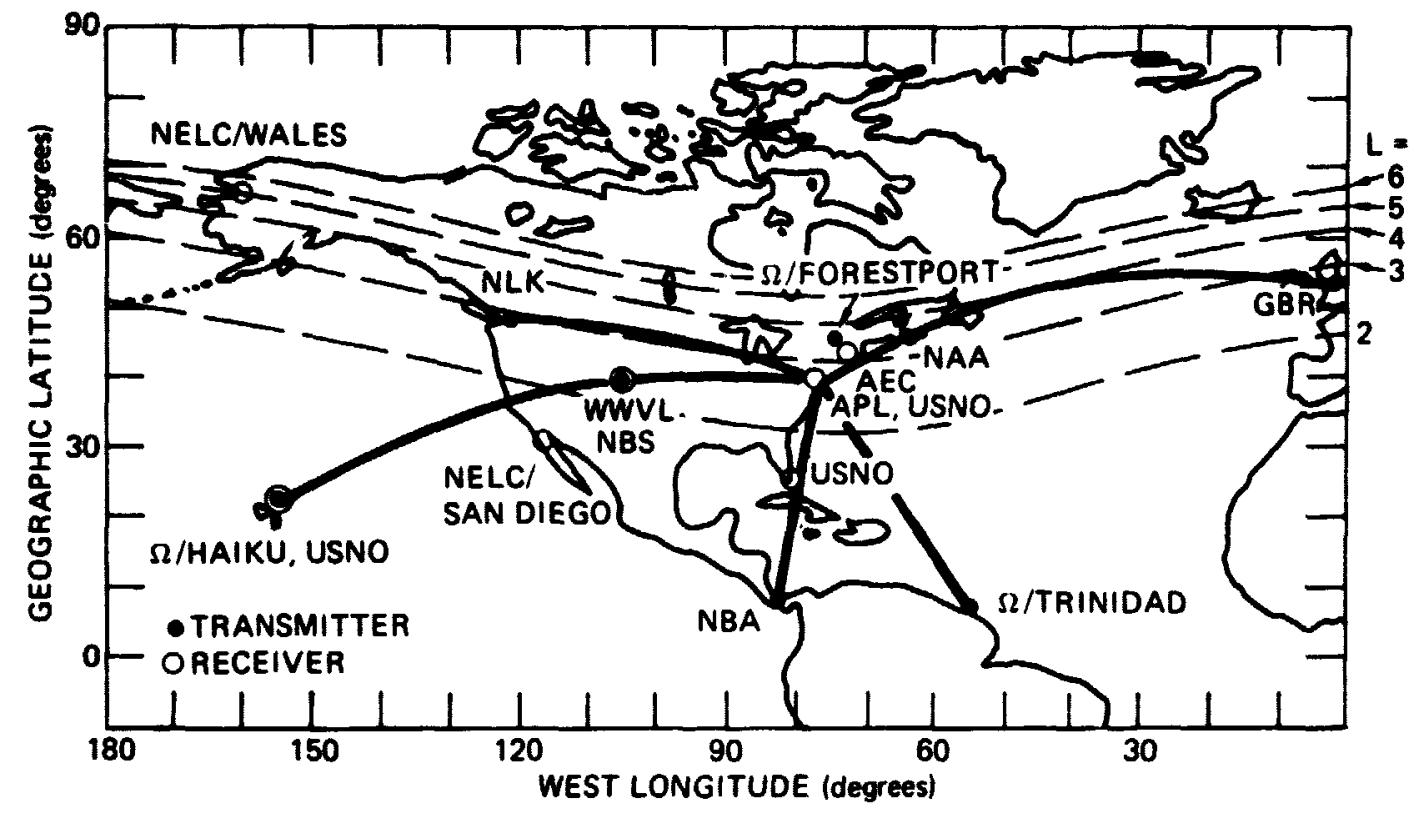

Figure 1. VLF Transmission Paths Monitored at API, and the U.S. Naval Observatory with Projections of Magnetic L Shells at $100 \mathrm{~km}$ Altitude (from Wiley and Barish, 1970).

Table 1

VLF Propagation Paths

\begin{tabular}{|l|c|c|c|c|c|}
\hline \multicolumn{1}{|c|}{ Path } & $\begin{array}{c}\text { Freq. } \\
\mathrm{kHz}\end{array}$ & $\begin{array}{c}\text { Distance, } \\
\mathrm{km}\end{array}$ & $\begin{array}{c}\text { Highest } \\
\text { Geographic } \\
\text { Latitude }\end{array}$ & $\begin{array}{c}\text { Highest } \\
\mathrm{L}(\mathrm{A})\end{array}$ & $\begin{array}{c}\Delta r / \Delta \mathrm{h} \text { at } 70 \mathrm{~km} \\
\mu \mathrm{sec} / \mathrm{km}\end{array}$ \\
\hline $\begin{array}{l}\text { GBR-APL } \\
\text { (Rugby, } \\
\text { England) }\end{array}$ & 16.0 & 5615 & $54.4^{\circ}$ & $\begin{array}{c}4.0 \\
\left(60^{\circ}\right)\end{array}$ & 2.9 \\
$\begin{array}{l}\text { NLK-APL } \\
\text { (Jim Creek, } \\
\text { Wash.) }\end{array}$ & 18.6 & 3730 & $48.2^{\circ}$ & $\begin{array}{c}3.5 \\
\left(57.5^{\circ}\right)\end{array}$ & 1.8 \\
\hline
\end{tabular}


employ the exponential conductivity model of the lower ionosphere, a uniform $1 \mathrm{~km}$-lowering of the ionospheric reference height without a change of gradient will produce a $2.9 \mu \mathrm{sec}\left(2.9 \times 10^{-6} \mathrm{sec}\right)$ advance in the phase of the GBR transmission as received at APL. The phase advance (or retardation) corresponding to a $1 \mathrm{~km}$-lowering (or raising) of the effective height near $70 \mathrm{~km}$ for the NLK-APL path was computed in the same manner and is also listed in Table 1. These phase calculations may be applied to the VLF transmissions received at the U.S. Naval Observatory because this station is close $(\sim 30 \mathrm{~km})$ to $\mathrm{APL}$.

During the first three months of 1965 (the first period analyzed here) the frequency of most VLF transmitters was controlled by crystal oscillators which drifted in frequency and the refore in phase to such an extent that meaningful studies of long-period (>10 days) variations are difficult if not impossible. The $16 \mathrm{kHz}$ transmission from station GBR in Rugby, England, was unique during this period since the frequency of this transmission was compared on a daily basis to a cesi':si atomic standard located nearby at the National Physical Laboratory, Teddingion, Middelsex, England. The average frequency deviation of the GBR transmissions over a 24-hour period was measured and recorded (Pierce et al., 1960; Reder, private communication, 1973). The received transmission at APL was also compared to a cesium reference which is part of the receiving facility. The NLK transmitter oscillator was put under direct cesium control in May 1967. Before then the day-to-day variations in the NLK data $( \pm 10 \mu \mathrm{sec})$ were often very much larger than the GBR variations $( \pm 2-3$ $\mu \mathrm{sec})$. This makes the use of the NLK data extremely difficult for a long-period analysis and may explain in part the poor correlations obtained using the NLK transmission data for 1965 .

With transmitter and receiver oscillators controlled by cesium standards, the precision of the frequency measurement is better than a few parts in $10^{11}$, so that the relative phase delay at APL or USNO can be determined with a precision less than a $\mu$ sec in a 24-hour period. Thus, variations in the fonospheric waveguide height that produce phase changes more than a few $\mu$ secs in a 24-hour period can be detected. Since a $\pm 1 \mathrm{~km}$ uniform change over the GBR-APL path would produce $a \pm 2.9 \mu \mathrm{sec}$ change in relative phase, we may expect to be able to detect height fluctuations of this magnitude.

The GBR transmitter oscillator was placed under direct control of a rubidium standard in 1967 which considerably reduced the longterm frequency drift (although not as effictively as by the cesium standurd). A parabolic phase varjation was subtracted to correct for this drift in the GBR-USNO phase data during the 1969 period presented here. 
All the VLF data presented here were subjected to a five-day running mean.

The VLF phase variations may be considered as representative, approximately, of the variations of the reflection height averaged over the transmission path. For comparison with electron density variations calculated from the lonospheric soundings at Aberystwyth, and with meteorological data estimated for particular longitudes (see next section) we can consider the VLF phase changes to correspond to horizontally averaged observations over the midpoint of the path, that is about $40^{\circ} \mathrm{W}$ for the GBR path and $100^{\circ} \mathrm{W}$ for the NLK path.

\section{METEOROLOGICAL DATA}

The geopotential heights at various latitudes and levels had been subjected to longitudinal Fourier analysis previously in connection with another study (Deland 1973). Since the VLF paths are relatively long, and also because previous work has indicated that the largest scale variations extend upward to a greater extent than the smaller scales, we have calculated values of the geopotential height at a particular longitude by summing the contributions of the first three zonal wavenumbers 1,2 and 3. These longitudinally smoothed values of geopotential height were then subjected to a longitudinal and time-lagged auto-correlation analysis ("auto" because it is the same variable at different places and times that is being correlated), the height fluctuations at four different longitudes being correlated with the fluctuations at zero longitude. Lag correlation coefficients were calculated for $y_{\lambda}(t+\tau)$ and $y_{0}(t)$ where $y_{\lambda}$ and $y_{0}$ are the geopotential height values at longitude $\lambda$ and zero, respectively, and $\tau$ is the delay in days at longitude $\lambda$ relative to longitude zero. The results are presented in Figure 2.

The zero and $90^{\circ} \mathrm{W}$ longitude graphs for 1965 (Fig. 2a) are almost opposite in phase, 80 the fluctuations appear to correspond to a wavelength of approximately 180 degrees, that is, the three harmonics average out to essentially a "wave two" pattern. It is also apparent from all four graphs of 1965 that the best positive correlation is found for increasing lag as longitude $\lambda$ increases corresponding to the composite wave moving eastward with an average speed of the order of 8 degrees of longitude per day.

In 1969 , a comparison of the $45^{\circ} \mathrm{E}$ and $90^{\circ} \mathrm{W}$ graphs (Fig. 2b) indicates that the average half wavelength of the compuiti. wave is of the order of 135 degrees, somewhat longer than in 1965. The composite wave for 1969 is apparently moving westward (increasing lag westward) with a.n average speed of about 15 degrees of longitude per day. 
(a) (b)

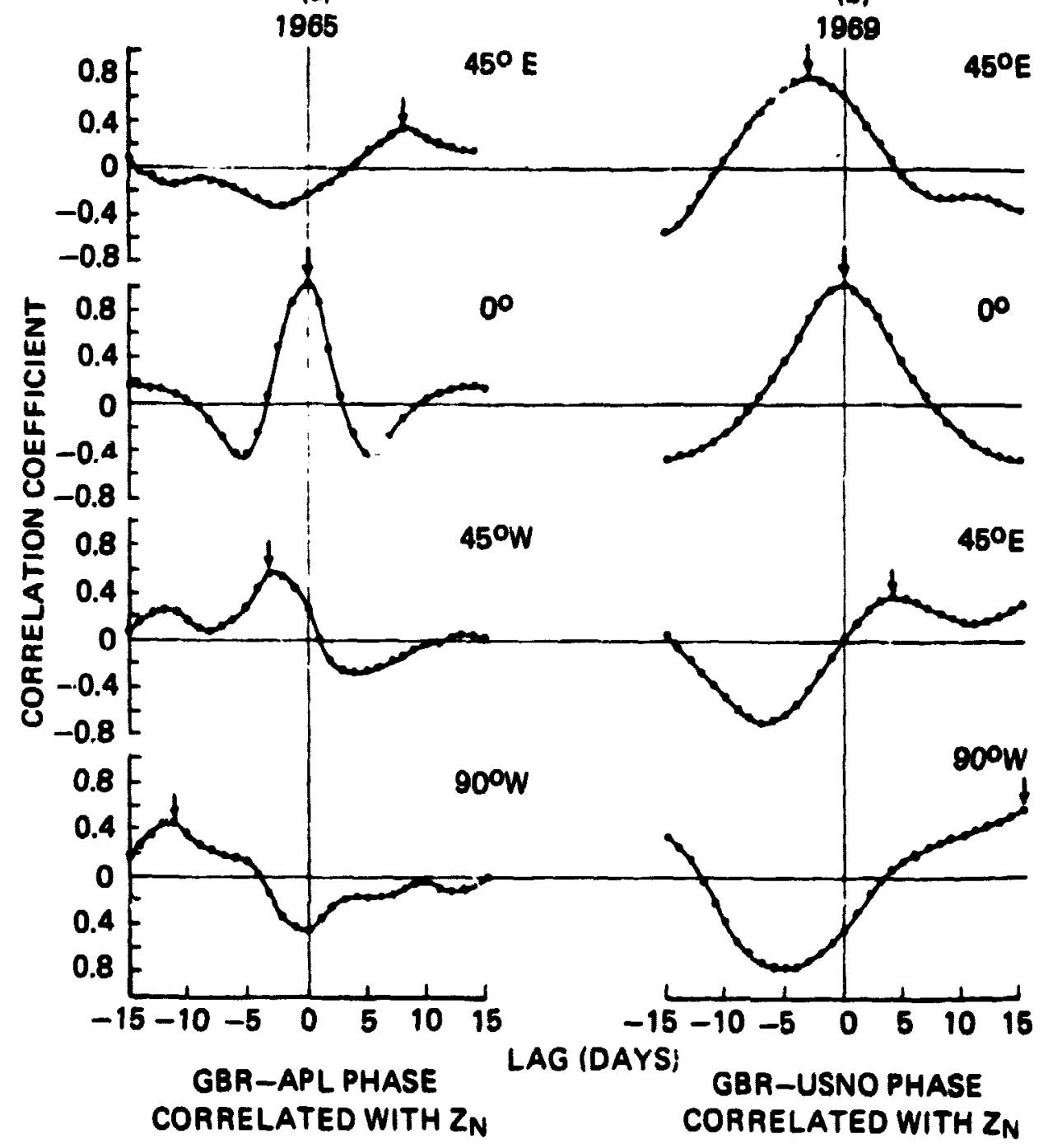

Figure 2. Auto-Correlations of the Variations of $10 \mathrm{mb}$ Geopotential Height Corresponding to the First Three Harmonics Relative to Zero Longitude for the First Three Months in (a) 1965 and (b) 196.9 .

\section{COMPARISON OF IONOSPHERIC AND METEOROLOGICAL DATA}

The running 5-day average of the daytime relative phase delay for the GBRAPL path is plotted in Figure 3 for the first three months in 1965 . The relative phase is measured in units of $\mu \mathrm{sec}\left(10^{-6} \mathrm{sec}\right)$. The effective reflection height, computed by the method described earlier, relative to a $70 \mathrm{~km}$ height, is also indicated in this figure. Also shown in Figure 3 are the variations of the 


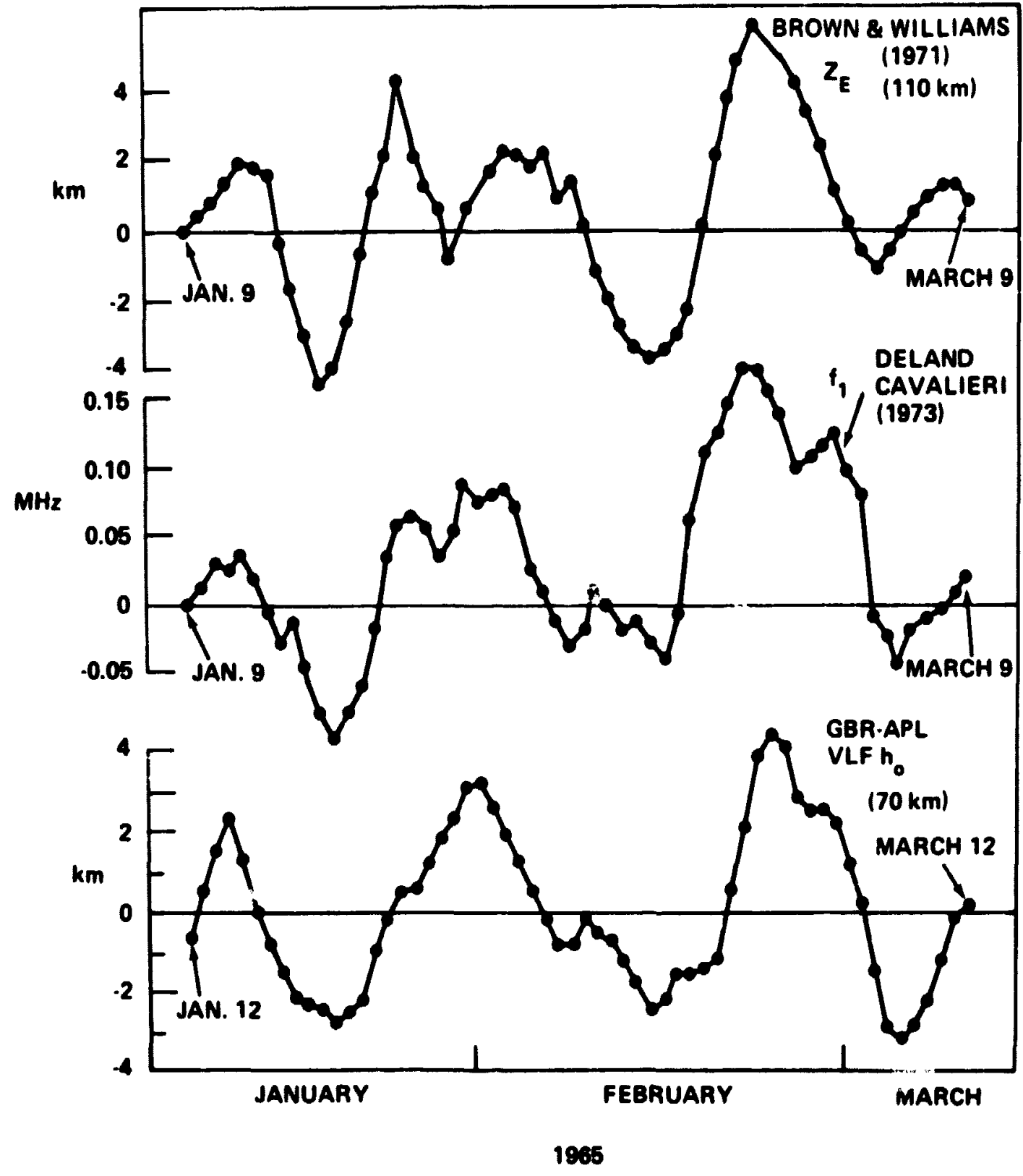

Figure 3. The Height $\mathrm{Z}_{\mathrm{E}}$ of the Constant Electron Density Surface for $\mathrm{N}=$ $4.5 \times 10^{4}$ elec $/ \mathrm{cm}^{3}$ in the E-Region over Aberystwyth from Brown and Williams (1971), the Interpolated Values of $\mathrm{f}-\mathrm{min}$ at Zero Longitude Corresponding to Zonal Wave Number 1 ( $\left.f_{1}\right)$ from Deland and Friedman (1972), and the Running 5-day Average of the Daytime Relative Phase Delay of the GBR-APL Path for 1965. 
interpolated values of $\mathrm{f}-\mathrm{min}$ at zero longitude corresponding to zonal wave number $1\left(f_{1}\right)$ determined by Deland and Friedman (1972) and the height $Z_{E}$ of the constant electron density surface for $\mathrm{N}=4.5 \times 10^{4} \mathrm{elec} / \mathrm{cm}^{3}$ in the E-region derived by Brown and Williams (1971) from ionograms measured at noon at Aberystwyth (located near the GBR transmitter at Rugby). The three different ionosphere measurements shown in Figure 3 appear to be well correlated when the VLF data are delayed by about 3 days with respect to the $f_{1}$ and $Z_{E}$ data.

The same GBR-APL phase variations are plotted in Figure 4 with the geopotential height corresponding to the sum of the first three Fourler harmonics computed for each day at $50^{\circ} \mathrm{N}$ geographic latitude and $90^{\circ} \mathrm{W}$ longitude. The "daily equivalent planetary amplitude" $A_{p}$ (Rostoker, 1972) is used here as the daily over-all index of magnetic activity and is also plotted in Figure 4. The times of polar cap absorption events (PCA's) and geomagnetic storm sudden commencements (SC) are also indicated in this figure and their effect on VLF signals will be discussed later.

The running 5-day average daytime relative phase delay for the NLK-USNO transmission during the first three months of 1960 are plotted in Figure 5. The height of the $10 \mathrm{mb}$ surface at zero longitude calculated from the first three zonal harmonics at $50^{\circ} \mathrm{N}$ geographic latitude is also plotted in this figure, but shifled to 4 days later with respect to the VLF data. The $A_{p}$ indices and times of PCA's and SC's are plotted in Figure 5 on the same time scale as the VLF data.

In Figure 6 the results of a lagged cross-correlation between the VLF phase data and the $10 \mathrm{mb}$ geopotential height data are presented for several longitudes for both periods analyzed.

\section{DISCUSSION}

The comparison of the GBR VLF phase fluctuations with the $90^{\circ} \mathrm{W}$ component of the $10 \mathrm{mb}$ data for 1965 (Fig. 4) shows the two time series to be well correlated when the latter is lagged by about fourteen days. The correlation is 0.67 which is signiffoant at the 0.025 level assuming 11 degrees of freedom for a sample of 56 data points using the "Student's" $t$ statistic (but of course the choice of lag is also relevant in estimation of significance). There is also a good correlation between the VLF and the $10 \mathrm{mb}$ data ai $45^{\circ} \mathrm{W}$ longitude when the VLF is lagged by 9 days. The correlation is 0.65 at the 0.01 level assuming 12 regrees of freedom from a sample of 61 . The best positive correlation at zero longitude is 0.36 at the 0.2 level with a lag of 4 days.

In Figure 6a the lag correlation coefficients mentioned above are marked by arrows at each longitude. The lag correlation curves for $45^{\circ} \mathrm{E}$ and $45^{\circ} \mathrm{W}$ are almost 


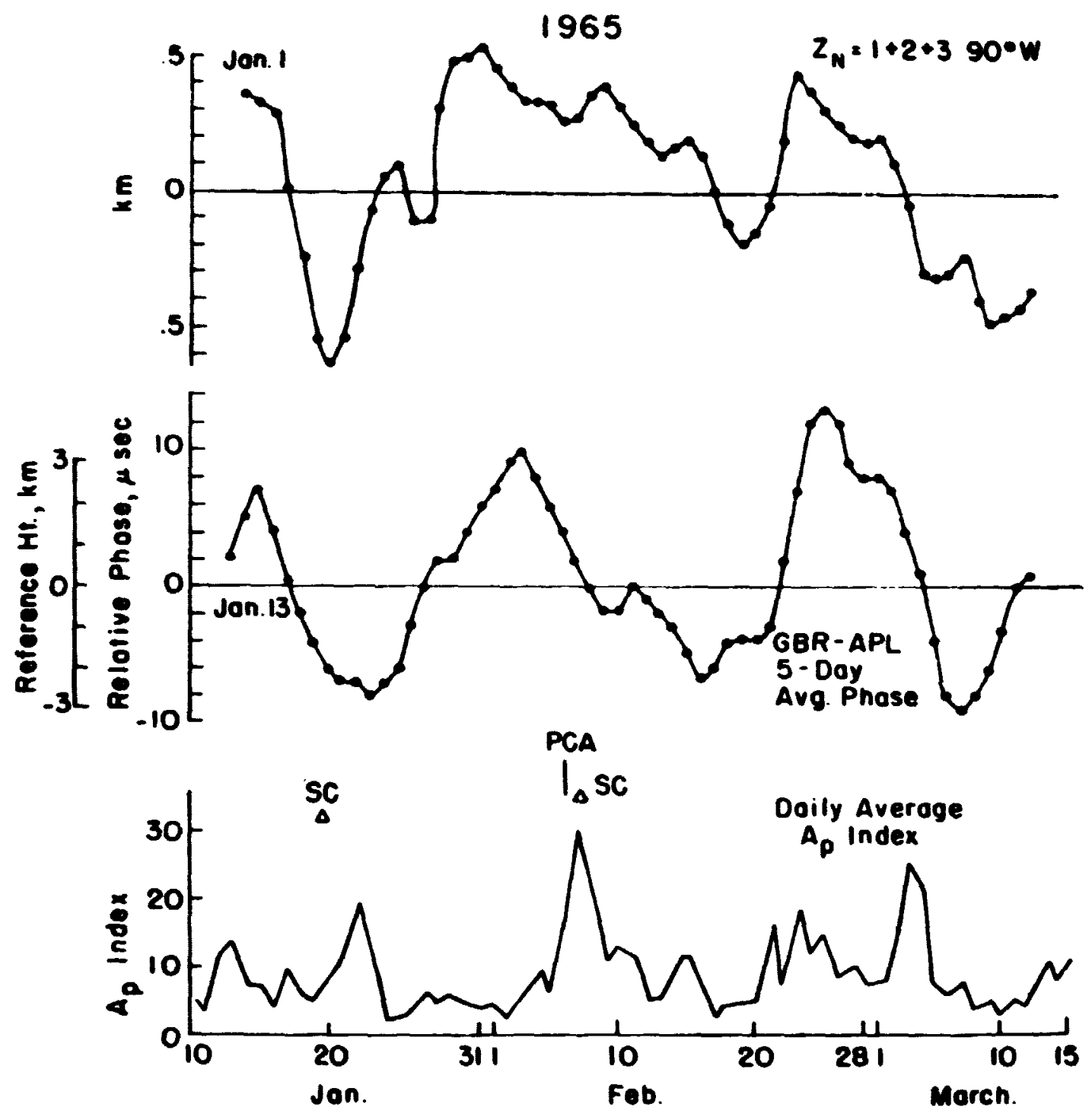

Figure 4. The $10 \mathrm{mb}$ Geopotential Height Curresponding to the Sum of the First Three Fourier Harmonics at $50^{\circ} \mathrm{N}$ Geographic Latitude and $90^{\circ} \mathrm{W}$ Longitude, the Same GBR-APL Phase Variation from Figure 3, and the Daily Equivalent Planetary Amplitude Ap (Solar Geophysical Data, U.S. Department of Commerce).

$180^{\circ}$ out of phase corresponding to a wave two pattern (that is the VLF data are correlated with an average two pattern) in agreement with the auto-correlation of the $10 \mathrm{mb}$ height data for 1965 (Fig. 2). It is apparent from an inspection of the correlation curves for all four longitudes that the VLF correlated fluctuations at $10 \mathrm{mb}$ are travelling eastward (increasing lag eastward) with an average speed of approximately 8 degrees of longitude per day which is again in agreement with 


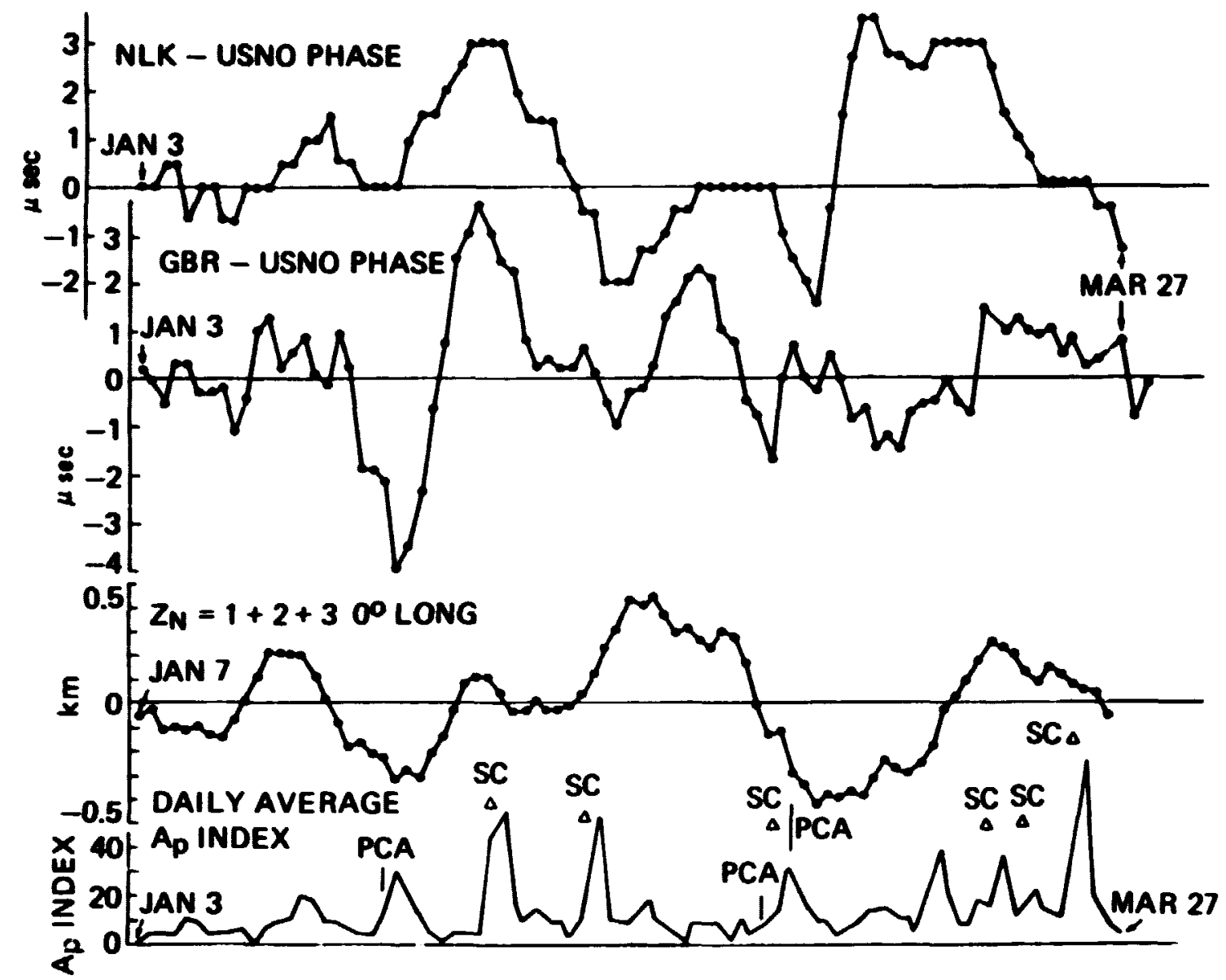

Figure 5. Running 5-Day Average of the Daytime Relative Phase Delay for the GBR and NLK Transmissions Received at the U.S. Naval Observatory, the Height of the $10 \mathrm{mb}$ Surface Calculated from the First Three Zonal Harmonics at a $50^{\circ} \mathrm{N}$ Geographic Latitude and $0^{\circ}$ Longitude, and Daily Equivalent Planetary Amplitude $A_{p}$ for the First Three Months of 1969.

the speed of the wave at $10 \mathrm{mb}$. Therefore, from a comparison of Figures $2 \mathrm{a}$ and $6 a$, it may be tentatively concluded that there are fluctuations at $70 \mathrm{~km}$ moving eastward with approximately the same speed as those at $30 \mathrm{~km}(10 \mathrm{mb})$. Also, from Figure 6a, the correlation between the VLF data (for $0-75^{\circ} \mathrm{W}$ ) and the $10 \mathrm{mb}$ height data is greatest at zero lag around zero longitude as. $45^{\circ} \mathrm{E}$, indicating westward tilt with height. Since the waves appear to be moving eastward, the 3-day delay of the GBR-APL phase with respect to the $f-\min$ and $\mathrm{z}_{\mathrm{E}}$ variations (which are dependent upon ionization changes at higher altitudes than the daytime VLF reference height) indicate an eastward tilt above $70 \mathrm{~km}$.

In 1969 the phase fluctuations are leading the $10 \mathrm{mb}$ geopotential height data (Fig. 5). The correlation of the VLF phase data when leading the $0^{\circ}$ longitude 


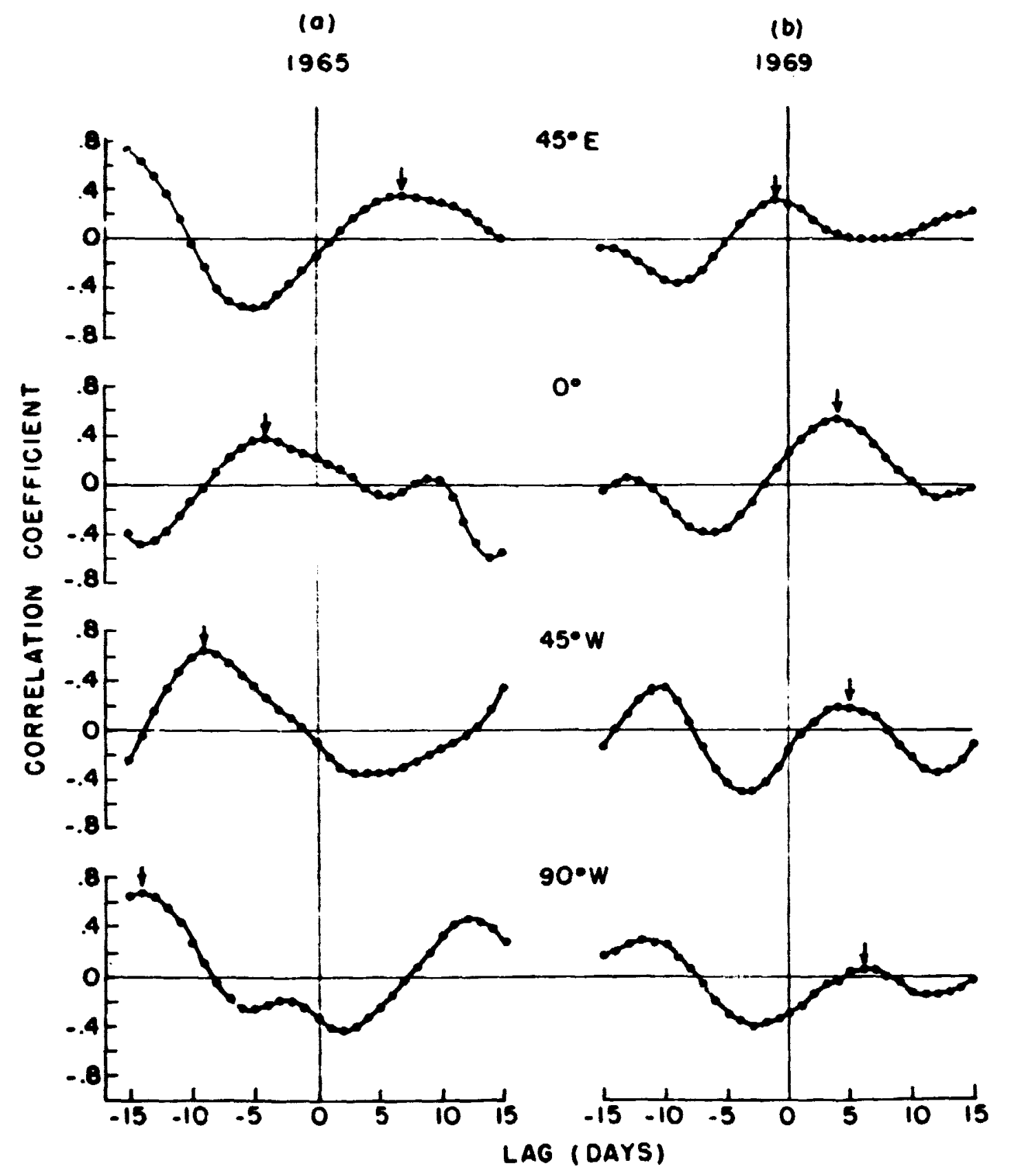

Figure 6. Cori elations Between (a) the GBR-APL Phase Variations and the $10 \mathrm{mb}$ Geopotential Height Data in 1965 and (b) the GBR-USNO Phase Variations and $10 \mathrm{mb}$ Geopotential Height Data in 1969 for Several Longitudes. 
geopotential height data by four days is 0.52 which is significant at the 0.025 level assuming 15 degrees of freedom for a sample of 76. The GBR fluctuations are almost in phase (time wise) with the geopotential fluctuations at $45^{\circ} \mathrm{E}$ (Fig. 6b). Inspection of Figure $6 \mathrm{~b}$ shows that the variations appear to be dominated by a wave one pattern (the correlation nearly reverses from $45^{\circ} \mathrm{E}$ to $90^{\circ} \mathrm{W}$ ) and that this pattern is moving westward (increasing lag westward) with an average speed of about 14 degrees of longitude per day, in agreement with the results at $10 \mathrm{mb}$ for the same period. Since the VLF phase flurtuations are almost in phase with the geopotential fluctuations at $45^{\circ} \mathrm{E}$, the wave apparently tilts westward with height. Summarizing the above, longitudinal phase relationships both in space and time presented in Figures 2 and 6 provide evidence of the existence of a westward tilted eastward travelling planetary scale wave during the 1965 period and a westward tilted westward travelling wave in 1969.

The longitudinal phase relationships discussed above for both periods analyzed were also present before smoothing of the VLF data, so these phase relationships are apparently real and are not due to averaging techniques.

Comparison of the phase fluctuations along the two paths analyzed (NLK and GBR) did not indicate any definite phase (longitudinal) relationship in 1965, which seems likely to be due to the severe frequency drifts of the NLK transmitter oscillator during that period.

In 1969 correlation of the NLK and GBR fluctuations computed over the whole period was weak. However, there appears (Fig. 5) to be a good correlation between the two paths for January and February. The reason for the poor correlation in March is not obvious, particularly since the entire 1969 period is marked by relatively high geomagnetic activity. A discussion of geomagnetic effects on VLF propagation is presented in the next section. The correlation between the phase fluctuations of these two indicate that the fluctuations at least during January and February were of large scale both in longitude and latitude.

The fact that the phase fluctuations along the GBR path correlate better with the $10 \mathrm{mb}$ data than do the fluctuations along the NLK path may be due in part to the lower geographic latitudes of the NLK transmission path. Studies made with shipborne absorption experiments (Schäning, 1973) have suggested that there may be a geographic latitude "cut off" around $35^{\circ} \mathrm{N}-40^{\circ} \mathrm{N}$ latitude for such events as variations of $D$-region absorption that are apparently due to planetary wave effects. Therefore, a southern boundary may exist $\left(\sim 40^{\circ} \mathrm{N}\right)$ south of which planetary scale wave transmission may be inhibited. Dynamical models (Dickinson, 1969; Matsuno, 1970) of upward transmission of planetary scale wave energy also indicate that such upward transmission should mainly occur in high latitudes. More significant correlations would then be expected at higher latitudes. 
Deland and McNulty (1973) have derived an approximate relationship for the time and zonal average energy conversion from the zonal flow to a traveling planetaryscale wave:

$$
\bar{C}_{T}=-\frac{U_{p}}{\sigma} \frac{k^{2}}{a \cos \varphi} \frac{\mathrm{Z}^{2}{ }_{T}}{2} \frac{\partial \lambda_{T}}{\partial p}
$$

where

$\lambda_{T}=$ the phase of the traveling wave

$\mathbf{p}=$ pressure

$\mathbf{Z}_{\mathrm{T}}=$ the amplitude

$\varphi=$ the latitude

$\sigma=$ the hydrostatic stability factor

$k=$ the zonal wave number

$\mathbf{U}=$ the eastward wind velocity

$\mathbf{U}_{\mathbf{p}}=\partial \mathrm{U} / \partial \mathbf{p}$

From this expression it follows that if the eastward zonal flow decreases with height (i.e. $\partial \lambda_{T} / \partial p>0$ ) the waves must tilt eastward with height for the energy conversion to be positive. On the other hand if the zonal flow increases $\mathrm{v}$. ith height then $\overline{\mathrm{C}}_{\mathrm{T}}$ will be positive only with a westward tilt with height.

From observational studies Deland (1973) has found that in the 'ower stratosphere at mid latitudes the traveling planetary scale waves apparently adjust their structure relative to the zonal flow so that energy is converted from the zonal flow to the waves at the levels studied.

In view of the fact that in winter the eastward zonal flow increases with height from $30 \mathrm{~km}$ up to the stratopause and than decreases, it is not surprising to find that the VLF fluctuations are lagging behind both the geopotential data at $10 \mathrm{mb}$ and $\mathrm{f}-\mathrm{min}$ and E-region electron density isopleths for the 1965 period (see Fig. 3). Although the height of the stratosphere is taken to be at about $55 \mathrm{~km}$ at mid latitudes, various studies have shown that winter mid latitude west wind maxima vary greatly. Maxima heights as great as $70 \mathrm{~km}$ have been reported (Batten, 1961).

The results obtained from the above correlations seem to be consigtent with the study made by Deland (1973). The tilt of the wave fronts of these transient planetary waves are such that energy on the average is converted from the zonal flow to the wave up to the E-region and possibly higher. Such an energy supply for the waves could compensate the losses due to radiational cooling, for example, as analyzed theoretically by Dickinson (1969). 


\section{PCA AND GEOMAGNETIC STORM EFFECTS ON VLF PROPAGATION}

The phase of midlatitude VLF transmissions during daytime conditions is not often affected by geophysical disturbances in comparison to high latitude or nighttime VLF transmissions. The daytime phase is sometimes disturbed by 1-10A $x$-rays during solar flares, but these effects usually last for less than 1 hour and cannot affect the slow planetary-scale variations analyzed in this paper. However, during PCA events, the sun can provide a sufficient number of energetic particles to penetrate down to a $70 \mathrm{~km}$ altitude and disturb VLF transmissions for long periods of time (e.g. 1 to 10 days). The excess ionization during PCA's is confined to the polar caps of the earth $\left(>63^{\circ}\right.$ geomagnetic latitude) except during severe magnetic storms when these effects extend to lower latitudes (Zmuda and Potemra, 1972).

The only PCA event that occurred during the first 3 months of 1965 began on February 5, 1965 and was relatively minor (producing a peak $30 \mathrm{MHz}$ polar cap riometer absorption of $1.8 \mathrm{db}$ in comparison to $12 \mathrm{db}$ for more severe events). Riometer measurements at several latitudes during this event by Bailey and Pomerantz (1965) indicate that ionization effects were negligible at or below $L=4$ (the highest L shell reached by the GBR-APL path).

The comprehensive review of VLF and LF propagation disturbances at midlatitudes associated with geomagnetic storms by Belrose and Thomas (1968) indicates these disturbances are "most marked during twilight and night hours, and are usually absent at noon." The geomagnetic storm which accompanied VLF disturbances presented by Belrose and Thomas were characterized by a range in the daily equivalent planetary amplitude $A_{p}=100$ to 150 . The largest $A_{p}$ value in the period 1 January to 20 March 1965, as shown in Figure 4, was equal to 31 following the storm sudden commencement (SC) during the PCA on February 5, 1965. Except for this minor PCA, the entire period during the beginning of 1965 can be characterized as magnetically quiet. It appears unlikely therefore, that the long-term variations in the GBR-APL phase shown in Figures 3 and 4 can be attributed to PCA or geomagnetic storm effects.

During the period 1 January to 27 March 1969, three minor PCA events occurred, which began on January 24, February 25, and February 27, with the peak $30 \mathrm{MHz}$ riometer absorption equal to $1.7 \mathrm{db}$. These are indicated in Figure 5 and there do not appear to be any clear effects on the GBR or NLK-USNO phase variations. For example, the relative phase on both paths began to decrease on 20 January 1969 preceding the January 24 PCA and the phase delay increased after this event, instead of decreasing as would be expected for polar VLF transmissions during PCA events. 
A large number of geomagnetic storm sudden commencements occurred during the beginning of 1969 and these are shown in Figure 5 with the daily planetary amplitudes $A_{p}$. The magnetic activity for the month of January 1969 is relatively low (maximum $A_{p}=29$ ) when the GBR-USNO phase delay reached its most negative value during the entire period shown in Figure 5. Because of the number of SC's in February and March 1969, it is difficult to prove conclusively that none of the VLF variations shown in Figure 5 are associated with magnetic storm effects. However, the level of geomagnetic activity during this period (maximum $A_{p}=62$ for February and maximum $A_{p}=79$ for March) is only moderate in comparison to the larger geomagnetic storms that have been observed to produce daytime mid-latitude VLF disturbances (Belrose and Thomas, 1968).

\section{CONCLUSION}

Comparison of VLF phase measurements with stratospheric geopotential height data indicate the presence of traveling planetary scale waves in the ionosphere.

The use of long distance VLF transmissions as an ionospheric probe is usually limited by the fact that localized disturbances (small in spatial extent compared to the path length) are difficult to detect. But, as shown here, the VLF phase data can be very effective for the study of planetary-scale disturbances. Further, the VLF is affected by a smaller altitude range of ionization in the D-region, in comparison to MF or HF absorption measurements, and is therefore, a more direct measure of small changes (about $\pm 1 \mathrm{~km}$ ) in the effective height of the ionosphere near a $70 \mathrm{~km}$ altitude.

For these reasons and as demonstrated here, stable-frequency VLF transmissions can serve as a useful tool for the study of stratospheric-ionosphere coupling. They should be especially useful in studying the vertical propagation of energy into the ionosphere in terms of the vertical structure of both the quasistationary and transient planetary scale waves.

The results presented in this paper appear to be consistent with requirements for upward p:opagation of energy.

It is hoped that further use of VLF transmissions in the study of transient planetary scale waves in the ionosphere will make possible the forecasting of meteorological effects on the ionosphere in the near future.

\section{ACKNOWLEDGEMENTS}

This work has been supported by the National Science Foundation, under Grant No. 25820. 
The work of T. A. Potemra and R. F. Gavin was supported by the Naval Ordnance Systems Command, Department of the Navy, under Contract N00017-72C-4401.

In the preparation of this paper, helpful discussions were held with Dr. F. H. Reder and B. W. Shaw.

The authors are grateful to Dr. G. M. R. Winckler and Miss M. Raines for the VLF data frorn the U.S. Naval Observatory, Washington, D.C. The Fourier harmonics of the geopotential data were computed by J. Shiau, using the CDC 6600 of the Courant Computing Center, New York University.

\section{REFERENCES}

Bailey, D. K. and Pomerantz, A. M., 1965, J. Geophys. Res. 70, 5823.

Batten, E. S., 1961, J. of Meteor. 18, 283.

Belrose, J. S. and Thomas, L., 1968, J. Atmos. Terr. Phys. 30, 1397.

Bowhill, S. A., 1969, Annls. IQSY 5, 83.

Boville, B. W., 1966, Space Research 1, 20.

Bracewell, R. N., Budden, K. G., Ratcliffe, J. A., Straker, T. W. and Weekes, K., 1951, Proc. Instit. Elec. Eng. 98, 221.

Brady, A. H. and Crombie, D. D., 1963, J. Geophys, Res. 68, 5437.

Brown, G. M. and Williams, D. C., 1971, J. Atmos. Terr. Phys, 33, 1321.

Charney, J. G. and Drazin, P. G., 1961, J. Geophys. Kes. $\underline{66}, 83$.

Deland, R. J., 1970, Q. J. R. Met. Soc. 96, 756.

Deland R. J., 1973, Tellus 25, No. 4, (In press).

Deland, R. J. and Cavalieri, D. J., 1973, J. Atmos. Terr. Phys. 35, 125.

Deland, R. J. and Friedman, R. M., 1972, J. Atmos. Terr. Phys. 34, 295.

Deland, R. J. and Johnson, K. W., 1968, Mon. Wea. Rev, $\underline{96}, 12$. 
Dickinson, R. E., 1968a, Mon. Wea. Rev. 96, 405.

Dickinson, R. E., 1968b, J. of Atmos. Sci. 25, 984.

Dickinson, R. E., 1969, J. of Geophys. Res. 74, 929.

Eliassen, A. and. $\operatorname{lm}$, E., 1960, Geofys. Publikajnoner $\underline{12}$, No. 3, 1.

Gregory, J. B. and Manson, A. H., 1969, J. Atmos. Terr. Phys. 31, 703.

Hirota, I., 1971, J. Met. Soc. Japan 49, 439.

Johler, R. J., 1970, Phase and Frequency Instabilities in Electromagnetic Wave Propagation p. 154, Technivision Services, Eng.

Lauter, E. A. and Taubenheim, J., 1971, Space Res. XI, 1005.

Matsuno, T., 1970, J. Atmos, Sci, 27, 871.

Noonkester, V. R., 1972, J. Geophys. Res. 77, 6592.

Pierce, J. A., Winkler, G. M. R., and Corke, R. L., 1960, Nature 187, 914.

Potemra, T. A., Zmuda, A. J., Shaw, B. W. and Haave, C. R., 1970, Radio Sci. $5,1137$.

Potemra, T. A. and Rosenberg, T. J., 1973, J. Geophys. Res. 78, 1572.

Reder, F. H. and Westerlund, S., 1970, Phase and Frequency Instabilities in Electromagnetic Wave Propagation p. 103, Technivision Service, Eng.

Rostoker, G., 1972, Rev. Geophys. Space Phys. 10, 935.

Schäning, B., 1973, J. Atmos. Terr. Phys. 35, 1003.

Schwentek, H., 1969, Space Res. IV, 405.

Thomas, L., 1971, J. Atmos. Terr. Phys. 33, 157.

Wait, J. R. and Spies, K. P., 1964, NBS Tech. Note 300.

Westerlund, S., Reder, F. H. and $\AA$ bom, C., 1969, Planetary Space Sc1. 17, 1329. 
Westerlund, S. and Reder, F. H., 1973, J. Atmos. Terr. Phys. (in press).

Zmuda, A. J. and Potemra, T. A., 1972, Rev. Geophys. Space Phys. 10, 981.

Reference is Also Made to the Following Unpublished Material

Deland, R. J. and McNulty, R., 1973, Paper presented at the Fifty-fourth annual meeting of the American Geophysical Union, April 16-20, 1973, Washington, D. C.

Wiley, R. E. and Barish, F. D., 1970, Plots of geomagnetic field geometry, Tech. Rept. AFWL-TR-69-144, Air Force Weapons Lab., Kirtland AFB, N. Mexico. 


\section{QUESTION AND ANSWER PERIOD}

DR. REDER:

Any questions, please?

MR. MERRION (Defense Mapping Agency):

I was wondering, what other implications would this have, other than for weather forecasting? Also is it possible to go backwards, do you think, to take the weather forecasts and predict something about your VLF transmissions?

DR. POTEMRA:

Absolutely. As a matter of fact, in response to your latter point there, that is exactly what we have been using.

At one point we weren't really cunvinced that the meteorological disturbances did have an effect on the ionosphere. There are many, many reasons why it should not, because there are various temperature minima as one plots temperature versus altitude.

And one would suspect that anything that happens on the ground would be insulated from the Earth's ionosphere that is so high up. There is no reason to expect why it should propagate upwards.

But we believe, by looking at the meteorological data first, and then correlating it with the VLF data, that there is a connection.

So, this is the direction that we have been going now.

I only mention that as a very, very low possibility of using the VLF to perhaps predict what is going to happen on the ground, because there is a great deal of interest; as you know, Walter R. Roberts is now advocating ' is theory that the interplanetary magnetic field can be used to predict weather, and things like this.

So, this is quite a controversial issue. But I think at the present point we can claim that by using the meteorological data, we can correlate it directly with ionospheric oscillations.

Now, as far as implication is concerned, I suppose if you are using the VLF as a time and frequency reference that you have to be concerned in the winter months as to long period stabilities and disturbances caused by the lonosphere, because some of these can come out to $20 \mathrm{microseconds}$ or 80 . 
But 1 am just not clear how this would work into a time and frequency network.

DR, REDER:

Coming back to your question, maybe that will be the only useful application of weather forecasting.

(Laughter.)

DR. REDER:

Any other questions? Yes, please.

DR. KLEPCZYNSKI:

I think there might possibly be another application. I haven't done any order of magnitude estimates on the back of an envelope yet, but if we have an idea from VLF how the atmosphere is acting, astronomers might be very interested in this because they might be able to get data on refraction.

DR. POTEMRA:

Oh, absolutely. If we look at some of the data that was presented on VLBI, for example those oscillations in the early morning hours seem to exhibit periods, I think, of 15 to 20 minutes. But in any case, it was reminiscent, not of planetary waves with 15 to 20 day periods, but of acoustic gravity waves that have been looked at in great detail. They have periods of 10 to 30 minutes, and they are often found after sunrise, because when the atmosphere gets a big blast of heat from the Sun it starts shaking. Also it is seen as the Sun sets, because that is when things cool down.

So, yes, I think that would be an important input to people for very long baseline interferometry.

DR. REDER:

I have a question, Dr. Potemra. Maybe I missed it when I was outside.

Isn't it so that this kind of an effect will be mostly seen on paths which are fairly high in latitude? 
DR. POTEMRA:

Yes, I didn't mention that, but this is a latitude restricted phenomena, and we just can't get anything from high latitude paths, because they are very disturbed by the auroras, as you will know from your work, but there appears to be a lower latitude cutoff also, and this cutoff occurs at about a 40 degree north geographic latitude. For example, the paths that we have down to Panama or to Trinidad, that is around the Equator or the Southern Hemisphere, there appears to be no variations of this sort. Professor Deland has an explanation for this, and it has to do with the propagation of the atmospheric disturbances.

But they are definitely restricted at latitudes above 45 degrees north geographic. If one gets higher than that, for example, up to 60 or 70 degrees geographic; then we would like to talk about geomagnetic latitude; and then we would have to be more concerned about short period disturbances due to particle precipitation and things like this.

DR. REDER:

Any more questions on this paper?

MR. CHI:

In your data which was presented, apparently you have correlated the nighttime phase record with magnetic disturbances.

DR. POTEMRA:

Yes.

MR. CHI:

What other parameters have you identified, temperature or --

DR. POTEMRA:

Now, you are referring to the nightcime disturbances correlated with the magnetic activity, is that right?

MR, CHI:

Right. 
DR. POTEMRA:

I went very quickly over that, because it is related to an analysis that we did about a year ago. I think Dr. Reder has quite a bit of experience in this area as well, but the situation is this, during the nighttime we very often see very small disturbances that are correlated with magnetic activity.

The question is why. Now, on one occasion, during a so-called magnetic substorm, measurements of precipitating electrons were made down at the South Pole, of all places, and also whistlers propagation, VLF emissions. These are long, very long frequency waves that propagate back and forth on the magnetic field lines.

They were also correlated with the onset of the same type of VLF disturbances, and on at least this one occasion we put together an argument that the VLF transmission phase disturbances were due to precipitating electrons that were being dumped out of the Van Allen radiation belt, and that these were due to these whistlers propagating back and forth, and that another manifestation of the substorm - now, it wasn't a big storm, a small storm - was the ground base magnetogram deflection.

Now, we have been trying to advocate the theory that when one sees these nighttime VLF disturbances, they are due to precipitating Van Allen electrons that are associated with magnetic disturbances.

Now, unfortunately, they occurred so often and it is very difficult to get all these things coordinated. But we think the evidence is very strong that this is the case.

Now, that has nothing to do at all with meteorological disturbances. I just wanted to pjint out that we have to sort out magnetospheric disturbances from meteorological disturbances, and one has to be very careful.

MR. CHI:

Did you correlate with respect to temperature, for instance?

DR. POTEMRA:

'n the metoerological disturbances, yes, we have done that as well because pressure and temperature would certainly work together, and there is an effect which has been long known, when one looks at absorption of HF radio waves, called the winter anomaly. During the winter months when the atmosphere cools down, they have observed for many, many years, 20 years, that the 
absorption, now, not VLF, the absorption disappeared as well. Not completely, but reduces, except on certain days, when the temperature increases on the ground for a few days - these are called stratospheric warmings - and the absorption also increases. This was first detected, I believe, by Professor Louckes in 1950 or 80 in Berlin, and it was called the "Berlin warming."

So, that is another manifestation, but VLF hasn't yet been used for this. But certair ly temperature correlations have been made, yes.

DR. REDER:

Any other questions on this paper?

(No response.)

DR. REDER:

So, let's start now with our general discussion of all the papers which have been given up to now, and who wants to ask a question or comment or anything?

Yes.

MR. MONTGOMERY (WSM, Nashville):

For several years we have been running phase recordings on WWVB at Nashville, and we have noticed on a number of occasions that there will be a shift about noontime on certain days.

I was just wondering if anyone else has noticed this? This is a shift that looks like the start of a diurnal shift, but it is only for a short period.

DR. REDER:

Is anybody here from the Bureau of Standards, or from the power companies, somebody who uses WWVB?

(No response.)

DR. REDER:

May I ask you, Mr. Montgomery, when was this? When did you observe it? 
MR. MONTGOMERY:

On a number of occasions in the past, but I don't have the data with me at present, but I can look this up. We have the records for the past three or four years.

DR. REDER:

And it happened at noontime, local noontime?

MR. MONTGOMERY:

Right, local noontime.

DR. REDER:

Well, was it an SID, maybe? How long did it last?

MR. MONTGOMERY:

A matter of an hour or so.

DR. REDER:

Well, it could be an SID.

Are there any other questions? Yes.

MR. MERRION (Defense Mapping Agency):

I have a question for Mr. Amlie of FAA.

I asked Dave Call this same question, but I guess I didn't get the intent of my question across.

The Air Force, or whoever is responsible for changing the name of that GPS so many times, is about to go ahead with the GPS - NAVSTAR system.

My question is not referred to the synchrodabs, but the astrodabs. Wouldn't it be reasonable to plan on using an astrodab syste:n to be compatible with the GPS system, rather than as a synchronous orbit system? 
MR. AMLE:

Let's see, how do I handle that answer?

First of all, the astrodab really isn't real. You know, it is fashionable to have a satellite program, so we have one.

\section{(Laughter.)}

I am serious. I own an airplane, and my wife and I share a checkbook, and I simply couldn't afford the kind of avionics that is required, to participate in a satellite system.

The military have a need for global coverage, they have a need for secure criptographic navigation and communications. Their needs are entirely different from the civil community, and they are willing to pay, as all we taxpayers know. It is entirely different. So, I think it is not reasonable.

DR. REDER:

Yes.

MR. MERRION:

In reference to what you just said about general aviation, someone who is in operations thought that proximity warning devices are the ideal collision avoidance system, and wouldn't something in this area, say, in infrared sensors, wouldn't this be the .....

MR. AMLIE:

Again, it is a matter of economics. The system that was used at Fort Rucker by the Army was a short range system, because they had a severe problem with helicopter training. As you know, they have a couple of square miles and an enormous number of helicopters, and they had a problem, they had people killed in collisions.

The equipment they bought was very short range, it was $\$ 5,000$ a unit. If you are to use it for fixed wing aircraft, it has to be, you know, much fancier, and the price goes up.

Our goal in the DABS operation is to have the entire avionics units under a thousand dollars. 
DR. REDER:

Any more questions on anything?

DR. WINKLER:

I would like to make a comment though and that goes back to the slide that you just gave.

I think there is one more point in the considerations, and that is 99 percent of all general aviation is not interested to find their location in the middle of the Pacific. They want to have something to go here in the Continental United States.

Now, for those few who are in the middle of the Pacific, or who are bush pilots in Northern Canada or in Alaska, there are additional systems which are economical and which are on the market today. I wanted to mention that, and also that they do not only use Omega, which at the moment is kind of frustrated because of a lack of operational transmitters. I imagine, of course, that this will eventually be done. There are stations on the air which are entirely compatible with Omega. These are the high power VLF stations, and I hope to hear a little bit more about this this afternoon.

They are being used for navigation by a large number of aircraft, already going into many hundreds of users.

What general aviation can do, other people can do as well, and I think the application of precise frequency control of VLF transmissions, be that now Omega transmissions, or be that the communications transmissions, is something which is still an important item, and it is for that reason that 1 think that research on prediction of propagation phenomena must continue.

We have had this morning the correlation with atmospheric phenomena, and I think that is just one of the things which we have not yet completely under control, and I think until we are in a position to set up somewhere and to have a predicted, accurate time of propagation from a station for a specific frequency we are still a little bit away from that.

Would you agree with that, Dr. Reder?

DR. REDER:

Yes. 
MR. WILSON:

I am Robert Wilson, from Aerospace Corporation, from the division that is involved with NAVSTAR.

As sort of an instant lay expert, I have been studying a lot of data that has been produced by many people in the audience. I would like to know why I have seen a great deal of data plotted as a variance of $\delta \mathrm{f} / \mathrm{f}$, but essentially no data plotted as a variance of $\delta \mathrm{t} / \mathrm{t}$, which is of considerable more interest to us, for example, than the frequency variation.

DR, REDER:

Well, if you give me your address, we could send you, for instance, as far as VLF is concerned, data on phase as a function of time.

I understand there are some data, for instance, on the change of the total electron content which can be related to the change in the time delay of satellite signals to ground stations. I am sure they are avallable from many sources, perhaps Dr. Soischer or Mr. Gorman who is here. He can take your address and send you data on that.

DR. WINKLER:

You may not have zeroed in on exactly the sense of the question here.

Frequency and Phase, the two are related. The sigma of a time variation, of course, is related to sigma of frequency va riations. It is very simple to convert one plot into the other, once you agree what you want to accept as a good statistical measure of time deviations.

One misunderstanding which I find most often in discussions about probable time deviations is the simple fact that the most likely position of your clock in any future moment will be with no time deviation. There is an equal probability for the clock to be late or slow (in relation to its extrapolated rate).

One has to keep that firmly in mind, that the most probable clock closure, or clock error when you resynchronize, is zero.

What we are talking about is the width of the distribution function of these clock errors when we make many synchronizations. This width is quite clearly related to the sigma/tau plots for frequency variations. 
I would use the following measure $\delta_{t}(\tau)=\tau \cdot \frac{\delta_{\Delta f}}{f}(\tau)$ and apply an additional fac-
tor $\sqrt{2}$ in order to be conservative. MR. WILSON:

Let me make the point that while these are convertible, it is not always easy to do, particularly for people who aren't experienced in the field of statistics.

Both for the Air Force and for engineers who are not experts in the field of frequency, and the field of time determination, it would be extremely convenient to have curves and data that show the way in which the errors in clocks over long periods of time will develop, and these simply don't seem to exist. At least we haven't been able to run them down.

Now, I understand from what you have said that this is available, and I will be glad to talk to you. But I did want to make that point, it is perhaps more a matter of laziness or inconvenience than the actual overall capability of being able to convert.

DR. WINKLER:

One source which is widely distributed and available is one of the older HewlettPackard catalogues. I don't know why HP, in the most recent catalogue has omitted the right-hand scale of the sigma tau plots. I think that they have been paying tribute to some perfectionist, because of the lack of standardization in sigma tau, or sigma subscript tau.

But I think it was a useful device, and maybe HP would like to respond to that question, why did you omit in your catalogue the right-hand side?

MR. BOURDET (Hewlett-Packard):

I think it was just a very simple economic move rather than anything else. We thought we could simplify the graph. We had to make it small in the catalogue and it was getting very confusing with so many lines.

DR. WINKLER:

Maybe, since this is a generally interesting question, I should rep.y to it more fully.

There is a considerable amount of information in the paper on characterization of frequency stability by Barns and co-authors, members of that commitiee, particularly see equation 39 on page 113 of the IEE E IM20 paper (May 1971). 
In addition, there have been publications where direct measures in time have been cited, e.g. our paper in metrologia Oct. 1970 or Cutler \& Venot, NEREM Record page 68,1968 . If you have a sigma tau frequency plot you add one to the slope, e.g. for a $-1 / 2$ slope in frequency you get a $+1 / 2$ slope in time, etc.

DR. REDER:

Any more questions?

(No response.)

DR. REDER:

Well, let me ask you one question.

Is there anybody here who has personal experience with the problem of precipitation statics on antennas used in aircraft navigation? Anyone?

MR. AMLIE:

Well, I can give a sort of an answer. It is a problem, precipitation static has been a problem for a long time in aircraft. There are some excellent little plastic widgets with very sharp needles which seem to solve the problem, certainly on HF, VHF is not a problem. It is a little plastic widget that works fantastically well down to VLF.

DR. REDER:

Well, maybe you should also get in touch with your people at Atlantic City, because they seem to have a problem.

MR. AMLIE:

Maybe they don't have some of these gadgets. I have one on my desk I can give them.

DR. REDER:

Any more questions, comments?

(No response.) 